\title{
Point to point multispectral light projection applied to cultural heritage
}

D. Vázquez, A. Alvarez, H. Canabal, A. Garcia, S. Mayorga, et al.

D. Vázquez, A. Alvarez, H. Canabal, A. Garcia, S. Mayorga, C. Muro, T. Galan, "Point to point multispectral light projection applied to cultural heritage," Proc. SPIE 10379, Nonimaging Optics: Efficient Design for Illumination and Solar Concentration XIV, 103790K (7 September 2017); doi: $10.1117 / 12.2281482$

EDIE Event: SPIE Optical Engineering + Applications, 2017, San Diego, California, United States 


\title{
Point to point multispectral light projection applied to cultural heritage
}

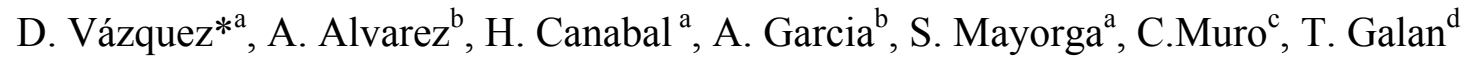 \\ a Optics Dept. of Universidad Complutense de Madrid, 118 Arcos del Jalón, Madrid,Spain,; \\ ${ }^{b}$ Dept. of Applied Physic, Universidad Politécnica de Madrid, Madrid, Spain,; \\ ${ }^{c}$ Restoration Dept. of CMuseo Nacional Centro de arte Reina Sofia, \\ ${ }^{\mathrm{d}}$ Dept. of R\&D LLEDO Iluminación, Mostoles, Spain.
}

\begin{abstract}
Use of new of light sources based on LED technology should allow the develop of systems that combine conservation and exhibition requirements and allow to make these art goods available to the next generations according to sustainability principles. The goal of this work is to develop light systems and sources with an optimized spectral distribution for each specific point of the art piece. This optimization process implies to maximize the color fidelity reproduction and the same time to minimize the photochemical damage. Perceived color under these sources will be similar (metameric) to technical requirements given by the restoration team uncharged of the conservation and exhibition of the goods of art. Depending of the fragility of the exposed art objects (i.e. spectral responsivity of the material) the irradiance must be kept under a critical level. Therefore, it is necessary to develop a mathematical model that simulates with enough accuracy both the visual effect of the illumination and the photochemical impact of the radiation. Spectral reflectance of a reference painting The mathematical model is based on a merit function that optimized the individual intensity of the LED-light sources taking into account the damage function of the material and color space coordinates. Moreover the algorithm used weights for damage and color fidelity in order to adapt the model to a specific museal application. In this work we show a sample of this technology applied to a picture of Sorolla (1863-1923) an important Spanish painter title "woman walking at the beach".
\end{abstract}

Keywords: LED, Lighting, cultural heritage, Color

\section{INTRODUCTION}

Care, preservation and exhibition of cultural heritage depend of environmental conditions of Museums ${ }^{1-4}$. Lighting is one of the most important parameters since it will permit to see the cultural goods but it will cause photoquimical degradation ${ }^{5,6}$.

It is not possible to light a piece of art without an irreversible damage, therefore conservation of cultural heritage and its associated artistic production raises two major problems. On the one hand, it is necessary to exhibit the artistic production which is the historical patrimony of a country. It is necessary to get high quality in luminance, uniformity, contrast and color reproduction. On the other hand, an adequate conservation of them requires, in order causing the minimal damage, to minimize the interaction of the artistic production exposed with the electromagnetic radiation ${ }^{7-11}$. In any case, two major requirements should be satisfied: to minimize the damage and to obtain a good color reproduction. For solving this complex problem we have to look for a compromise solution for the spectral reflectance since damage will be done by absorbed light and lighting quality will be obtained by reflected light. A parametric system will permit to study and to find out optimized solutions.

Action between light and matter is an important problem which takes influence about curator and museum's responsibles decisions. All institution where cultural heritage is showed to public must decide how they are going to light the goods since the preserve and exhibition criteria are opposite. The right decision about optimal solution between exhibition and conservation is a very complex problem and although there is no rational basic for deciding that certain rate of damage is acceptable.

a accuracy knowledge of degradation process will help to curator in that difficult decision. There is no a unique solution, and the optimal solution will be a function of several factors. The best decision will depend on the kind and importance

\footnotetext{
Nonimaging Optics: Efficient Design for Illumination and Solar Concentration XIV,

edited by Roland Winston, Sarah R. Kurtz, Proc. of SPIE Vol. 10379, 103790K

(C) 2017 SPIE · CCC code: $0277-786 X / 17 / \$ 18 \cdot$ doi: $10.1117 / 12.2281482$
} 
of the piece of art, properties of the matter with it is made, conservation status, exhibition time, environmental atmosphere, and so on. When a photon fall onto a material a chain of events begins but in any case when there is a change this will be irreversible and there will not be any security level for the radiation. There are four main factors which have influence about above mentioned effects on cultural goods and therefore the damage than a light source can produce in a cultural heritage:

-irradiance

- exposure time

-spectral distribution of light

- action spectra of material

Due to complex nature of cultural heritage goods it is very complex to determine the last one factor. Museums have to work with many different materials which are, in turn, in different conservation status. Many strategies have been proposed: take UV radiation out even until $400 \mathrm{~nm}$, reducing the radiation time by different strategies as switching off according with spectator presence, reducing exhibition time, exclusion of oxygen ${ }^{12}$, , refrigeration, and reducing light levels ${ }^{13-15}$.

Depending on wavelength when light fall onto paint surface it can be reflected or absorbed in different grades. Reflected light will permit to people see the painting and absorbed will cause damage in paint. No matter what wavelength of light we are using always a percentage of light will be absorbed even in that spectral region where pigment has not color. Therefore the first necessary data is spectral reflectance.

The colorimetric changes are quantitatively evaluated by computing the distances in the CIELAB space between the color stimulus evoked to the observer when illuminating with the reference light source (reference tristimulus values) and that color stimulus generated when other different illuminant. By using the relative spectral response function (damage function) proposed by the CIE .The procedure followed in this study can be applied to optimize the lighting systems used when illuminating any other kind of art work.

Nowadays new lighting system based on SSL sources permit to obtain spectral distributions optimized to requirements of museum exhibition and conservation beside another important advantages as energy consumption, life time, an so on $16-18$.

\section{LIGHT PROJECTION SYSTEM}

\subsection{Concept}

The goal of the system is to project on each point of the art good a light with an optimized spectral distribution in order to get the objective of the restauration staff. These objectives can be very different from one case to another. For example, in many cases museum responsible wants to get the same color that it is seen with a specific light source ${ }^{19}$ but with lower damage level $^{20}$, in others they could want to show the art good with a maximized gamut volume. In some cases the objective of the lighting system could be to compensate the yellowness of the varnish layer ${ }^{21} \mathrm{o}$ even to restore the color shift of the art good ${ }^{22}$. In this work we show develop the methodological concept and we have made a test with a reproduction of a paint of the Spanish painter Sorolla. He was a master in to express light effects and human feeling.

\subsection{Walk on the beach}

Walk on the beach is a paint of Joaquin Sorolla ${ }^{23}(1863-1923)$ which is characterized by a dexterous representation of the people and landscape under the bright sunlight of his native land, Valencia, and sunlit water. He was an master in to express light effects and human feeling. At the Paris Universal Exposition of 1900 won the medal of honour and his nomination as knight of the Legion of Honour. After this he was honoured as member of Fine arts academies of Paris, Lisbon and favourite son of Valencia. In 1908 he was a member of the Hispanic Society o America. He liked to paint big 
format paints at outdoor and under daylight scenes and portraits. The paint titled as Walk on the beach is an almost square paint of 2 square meters.
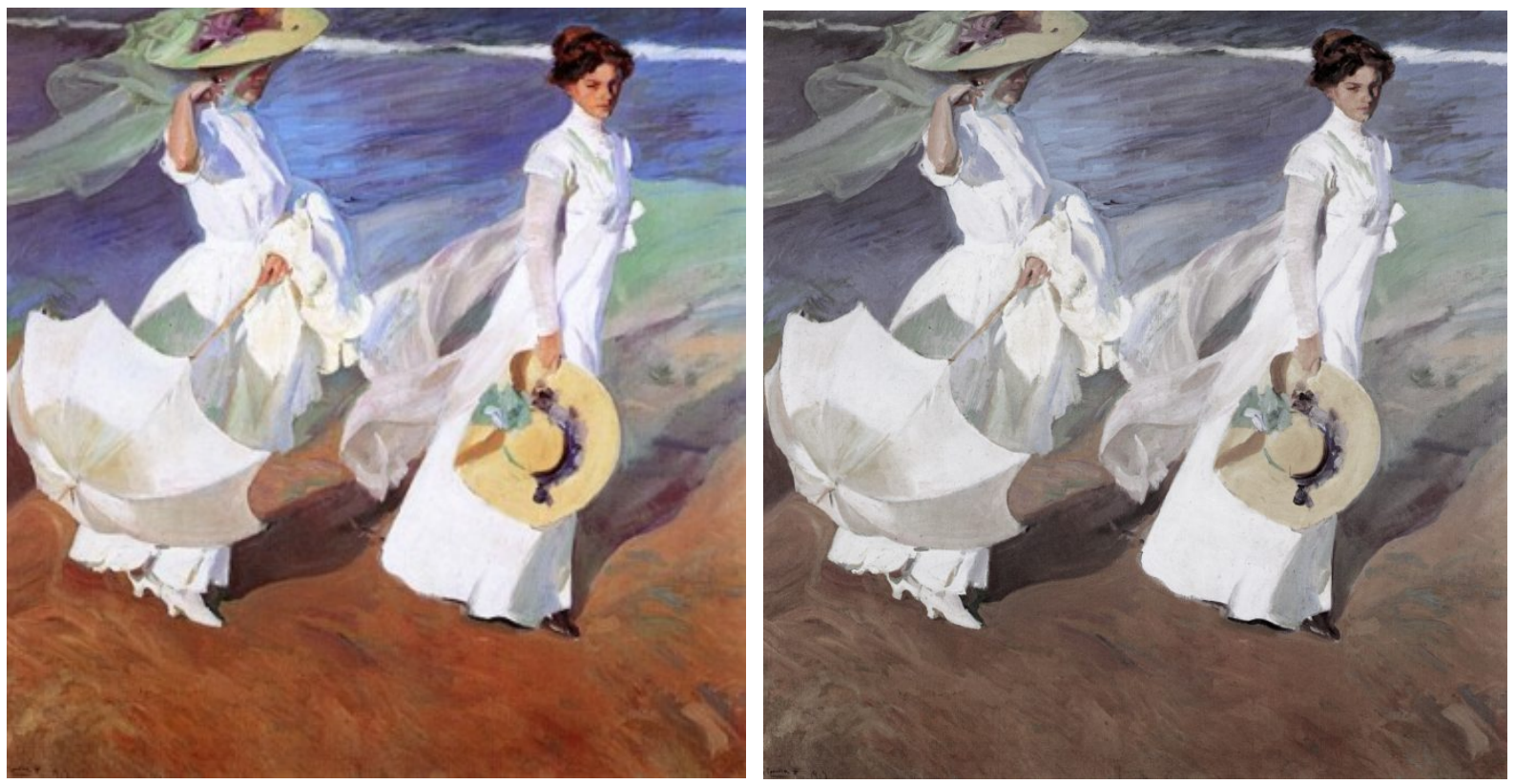

Fig.1.- Walk on the beach, Joaquin Sorolla 1909.Left original one painting, Right yellow shift painting.

Painted woman are Sorolla's wife Clotilde and his eldest daughter Maria. Sorolla painted this picture at the Playa of El Cabanyal in his hometown Valencia. Both women walk slowly and slightly, so that they appear to move toward the right edge. The daughter is looking towards the viewer while she has her yellow straw hat with a wide sweeping ring in the hand in fornt of the viewer and his wife stands straight while the sun and the wind play with them. No horizon is visible since the viewer is slightly rised. When Sorolla painted this picture he was extremely successful in Spain but in France and Germany too.

In order to develop this work we have made a copy of the paint with a yellow filter in order to reproduce a yellow shift by photochemical aging (Fig 1). The objective of the work in this case will be to recover the original one appearance, left image at figure1, lighting the aged picture with the developed lighting system( rught image at figure 1).

\section{SPATIAL AND SPECTRAL LIGHT SOURCE OPTIMIZATION METHODOLOGY}

The goal of the light projection system is to light each point of the paint with an optimized spectral distribution of light which the reflected light has the color coordinates that fit the restoration requirements. Proposed light system has for different components.

Goal parametrization of restoration requirements

Spectral reflectance characterization of paint

Light source spectral characterization

Optimization Algorithm

\subsection{Goal parametrization of restoration requirement}

This is one of the most difficult task of the project since here as the restoration staff as the technical one must work together. Responsible of the museum must decide how important is color reproduction and which is the ideal condition for the right perception of the art good. This question has not always a simple answer since the art good have usually very long and intensity history and many times they are a product of the original artist act but the time too. Material composition and its responsivity regarding visual radiation, the importance of the art good as the social, cultural and 
economic point of view must be taken into account. All this information must be translated to numerical parameters. Therefore is important that restorers and optical designers work together. In this task numerical model for aging of paints ${ }^{24}$ can be a very useful tool.

\subsection{Spectral reflectance characterization of paint}

In order to study the ideal color perception of the paint there are two different cases. First one would be when the original status of the painting is well characterized it is necessary to measure the spectral reflect. For example, when a painting has just been restored and its spectral reflectance has been measured. The second one case is more frequent and it happens when the painting is not recently restored and it suffer a color shift by photochemical process. In this second one case it will be necessary to study the original status by small sample cleaning or any another way of documentation as for example photo recording as it was used in Rothko paintings at Harvard. In this cases they used the original colour of the works was determined by the digital restoration of Kodak Ektachrome photographs taken in $1964^{25}$.

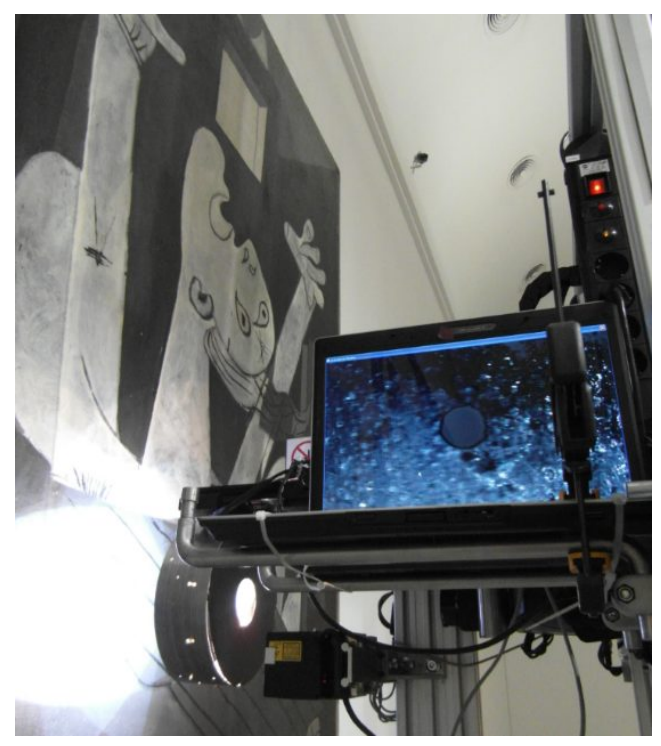

Fig.2.- Robot for point to point accuracy spectral reflectance characterization applied in the painting Guernica of Pablo Picasso at Museo Nacional Centro de Arte Reina Sofia in Madrid.

\subsection{Light source spectral characterization}

Since it is necessary point to point light control the light source is based on an imaging projection system with LED as a light source. Although a system with at least four LED would be better in this cases by cost limitations a RGB system has been applied. In each point of coordinates $(\mathrm{x}, \mathrm{y})$ we will have a spectral distribution $S_{\lambda(x, y)}$ defined as the sum of those three LED spectra.

$$
S_{\lambda(x, y)}=K_{R} R_{\lambda}+K_{G} G_{\lambda}+K_{B} B_{\lambda},(1)
$$

where $R_{\lambda}, G_{\lambda}, B_{\lambda}$ are the Spectral light distribution for Red, Green and Blue LEDs and $K_{R, G, B}$ are the ratio of intensity regarding of the maximum for these LEDs.

A very important requirement is the control of spectral distribution and when a specific spectral distribution is needed defined as the proportion of each used light source, the projection system must fit this distribution in its output light flux ${ }^{26}$. Usually due to electronic and thermal changes inside of the projection system this device change its behavior and when the projector is feed with $R_{\lambda}, G_{\lambda}, B_{\lambda}$ the spectral distribution of output flux $S_{\lambda}^{\prime}$ will be 


$$
S_{\lambda(x, y)}^{\prime}=K_{R}^{\prime} R_{\lambda}+K_{G}^{\prime} G_{\lambda}+K_{B}^{\prime} B_{\lambda}
$$

where $R_{\lambda}^{\prime}, G_{\lambda,}^{\prime} B_{\lambda}^{\prime}$ are the real intensity ratio of RGB LEDs.

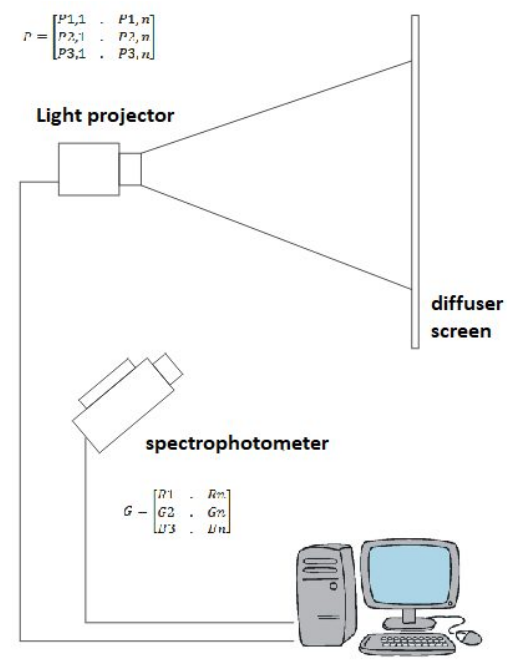

Fig.3.- Optical skecht of a LED plight projection system (left) and calibration setup (right).

Therefore for this kind of lighting system is essential an accuracy control of output lightflux. With regard to make this calibration a whole array of 546 squares with different proportions $K_{R}, K_{G} K_{B}$ is projected on a white lambertiam screen (fig.4)

$$
P=\left[\begin{array}{ccc}
P_{R, 1} & \ldots & P_{R, n} \\
P_{G, 1} & \ldots & P_{G, n} \\
P_{B, 1} & \ldots & P_{B, n}
\end{array}\right]
$$

Then its reflected spectral light distribution is measured with a noncontact spectrophotometer PR-655 and the real projected ratio is calculated.

$$
G=\left[\begin{array}{ccc}
P^{\prime}{ }_{R, 1} & \ldots & P_{R, n}^{\prime} \\
P_{G, 1}^{\prime} & \ldots & P_{G, n}^{\prime} \\
P_{B, 1}^{\prime} & \ldots & P_{B, n}^{\prime}
\end{array}\right]
$$

If a linear range is admitted we could express the relationship between P and G matrix as

$$
[G]=[A] \cdot[P],
$$

Where A would be a $3 \times 3$ matrix. With the objective of calculate matrix A we must solve the next system by least square

$$
|[A][P]-[G]|^{2}=0 .
$$


Therefore then we have $(A P-G)(A P-G)^{T}=(A P-G)\left(A^{T} \cdot A^{T}-G^{T}\right)$

If partial derivate of the function regarding

and therefore

$$
A \text { is } P P^{T}-P G^{T}=0 \text {, }
$$

$$
A^{T}=\left(P P^{T}\right)^{-1}\left(P G^{T}\right)
$$

and

$$
A=\left(A^{T}\right)^{T}
$$

With this calibration process the obtained error in each canal were $\varepsilon_{R}=0,0371, \varepsilon_{\mathrm{G}}=0,0358 \varepsilon_{\mathrm{B}}=0,0665$, and their standard deviation were $\sigma_{\mathrm{R}}=0,0021, \sigma_{\mathrm{G}}=0,0043$ and $\sigma_{\mathrm{B}}=0,0021$.

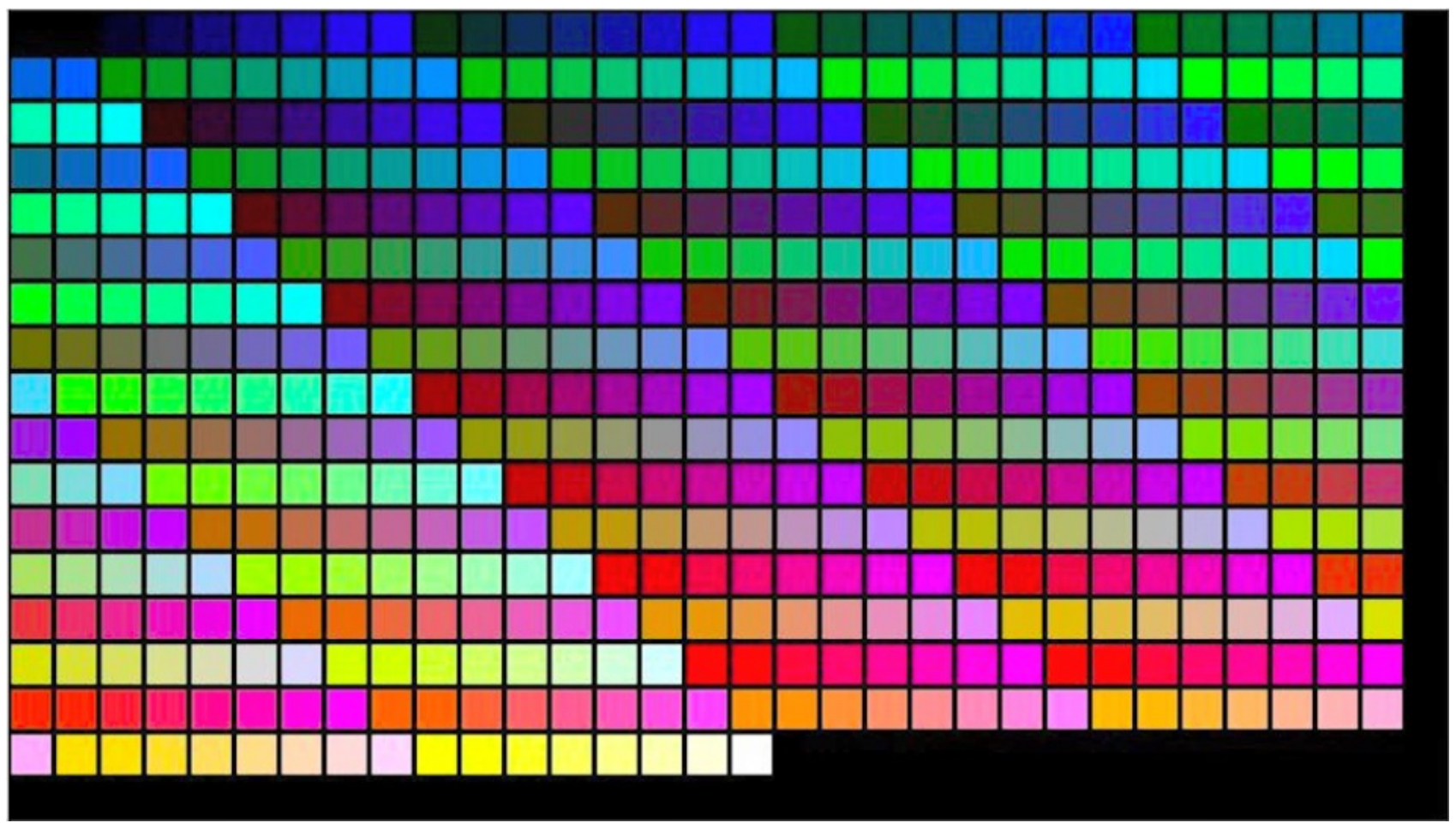

Fig.4.- Calibration grid with RGB projected pattern.

\subsection{Optimization algorithm}

One of the most important and difficult decision is to stablish the right conservation criteria and to translate these criteria in numerical parameters in order to computer and compare many possible solutions. Each one of these parameters will 
have its own weight in the optimization function: $C_{1}, C_{2}, \ldots, C_{\mathrm{m}}$. The applied optimization algorithm has to use two different information data: the first one is about color reproduction and other one is about damage evaluation. The system calculate for each point, with the predetermined resolution, the color coordinates under the objective light source, and estimated damage of the Paint. Depending on the type of light sources used in the optical projector, its spectral distribution can be modelled by parameters $k: k_{1}, k_{2}, \ldots, k_{n}$. Algorithm start with a specific spectral distribution which is defined by a vector of seed parameters. Then system calculates point by point, using the spectral reflectance the colour under the objective light source in CIELab coordinates and, using the absorptance, the damage associated with that spectral distribution defined by $k$ parameters. Then using Nelder-Mead the algorithm takes a decision about how to change parameters $k_{\mathrm{i}}$. (Fig.5)

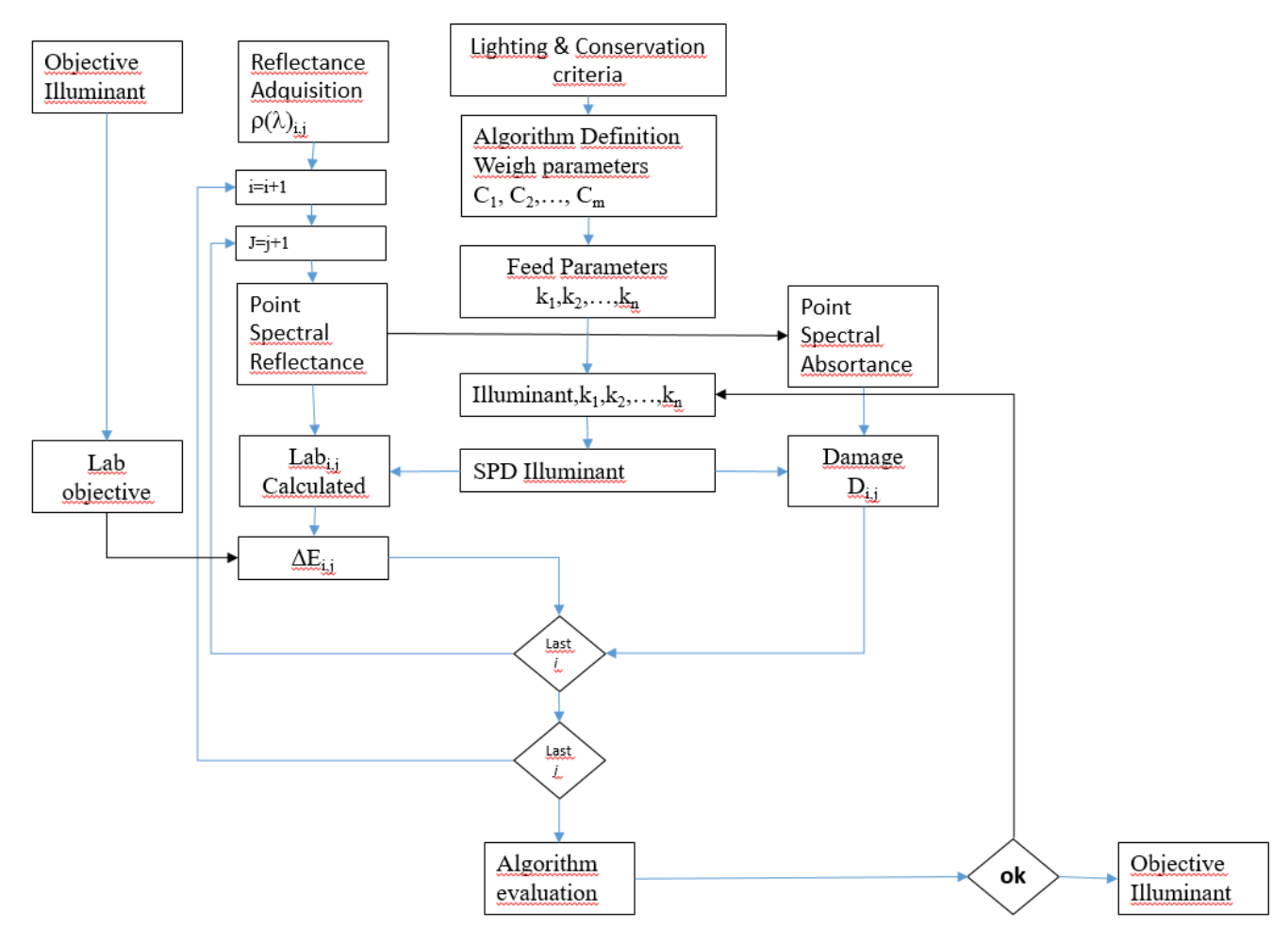

Fig.5.- Logic diagram of algorithm

After a number of reiterations, or when the solution is stable, the algorithm end and give us the vector with $k_{\mathrm{i}}$ parameters, which are the final solution.

\section{APPLIED EXAMPLE TO A PAINT OF SOROLLA}

In this work, the methodology has been applied to a copy of a paint of Joaquin Sorolla titled Walk on the beach. We have applied a digital yellow varnish to the paint and then we have printed the pint again. This print process has changed the color of the paint again according to own way. Then we have measured the spectral reflectance of this printed copy of the paint. In order to reduce calculation time we have taken only a matrix of $450 \mathrm{x} 411$ pixels. With spectral reflectance of each point, and using as light the source the spectral light distribution of an CIE $A$ illuminant Lab coordinates has been calculated. This calculation does near of 50 loops before take for good the solution but it only needs around 1,2 second ( in a i5 computer) by point. If the image were $1024 \times 1014$ it would need 15 computer days. I this example there are only $450 \times 411$ points and it needed $222 \cdot 10^{3}$ second that means $61 \mathrm{~h}$. In this case, we used 21 computer working in parallel. Used Light source is, in this case, a standard projector with RGB LEDs. 


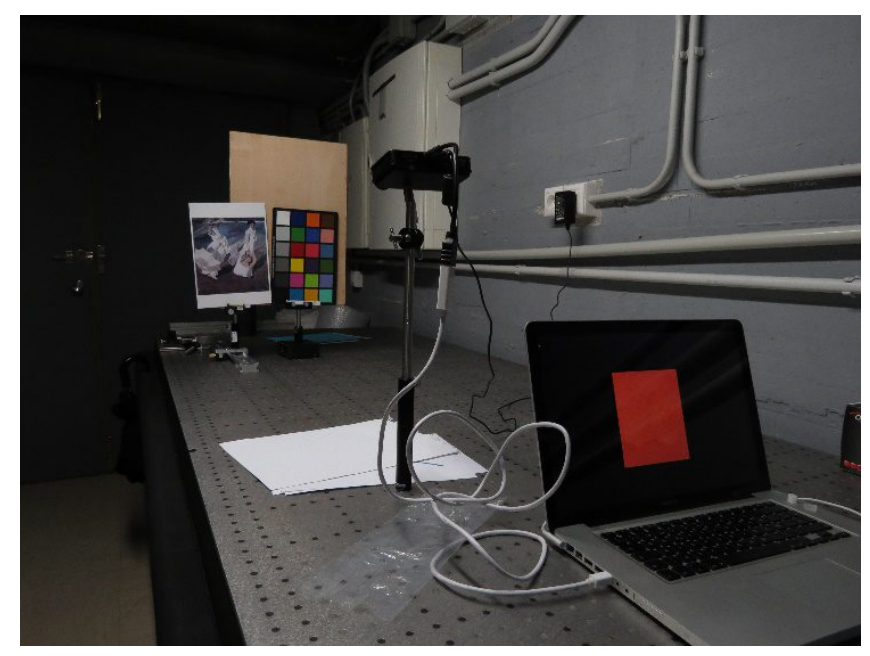

Fig.6.- System set up on the optics table at the photometry laboratory of Optics Faculty.

In the next figures, we show the obtained data for Lab coordinates. In Right image are the original Lab coordinates, before applied the yellow filter, and in the left image are the obtained coordinates after the light projection.

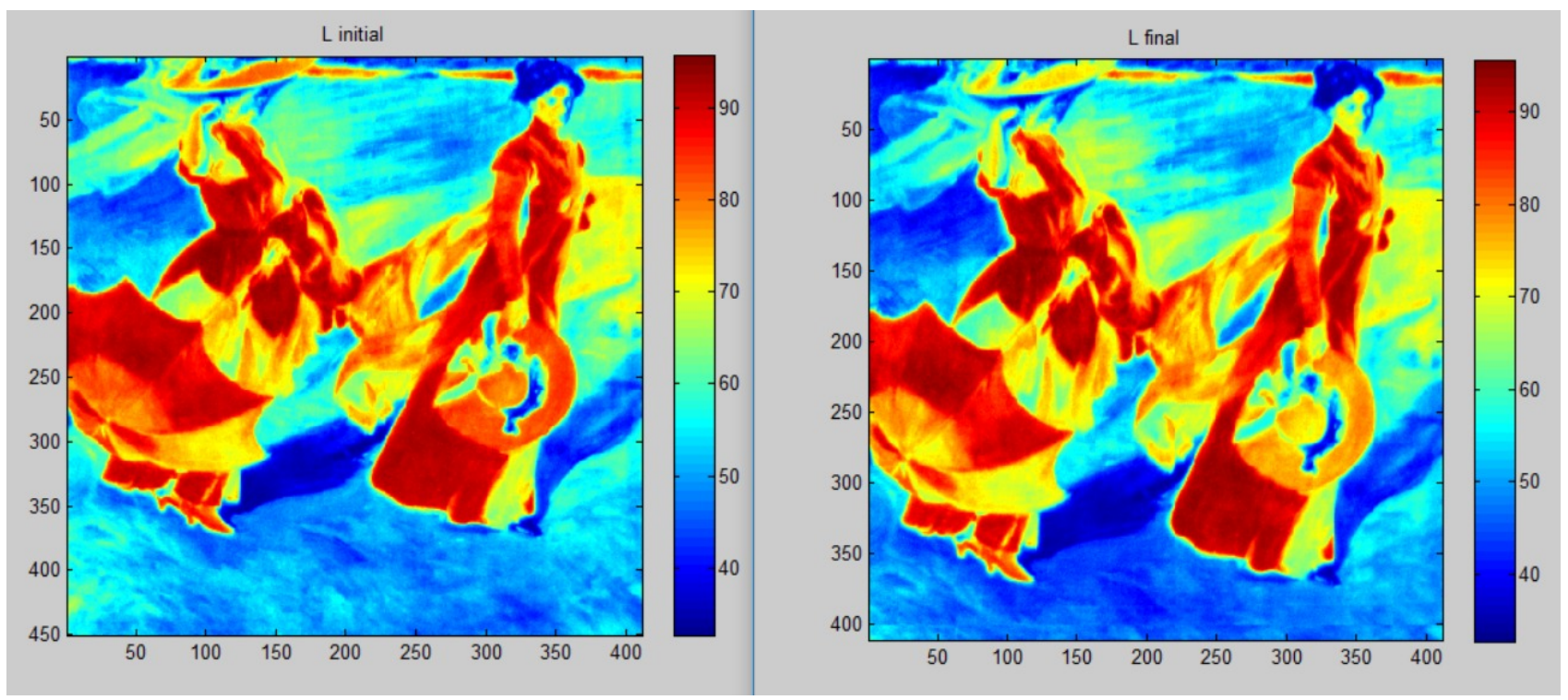

Fig.7.- $L$ coordinates on the paint. Original values (left) and obtained values (right) 


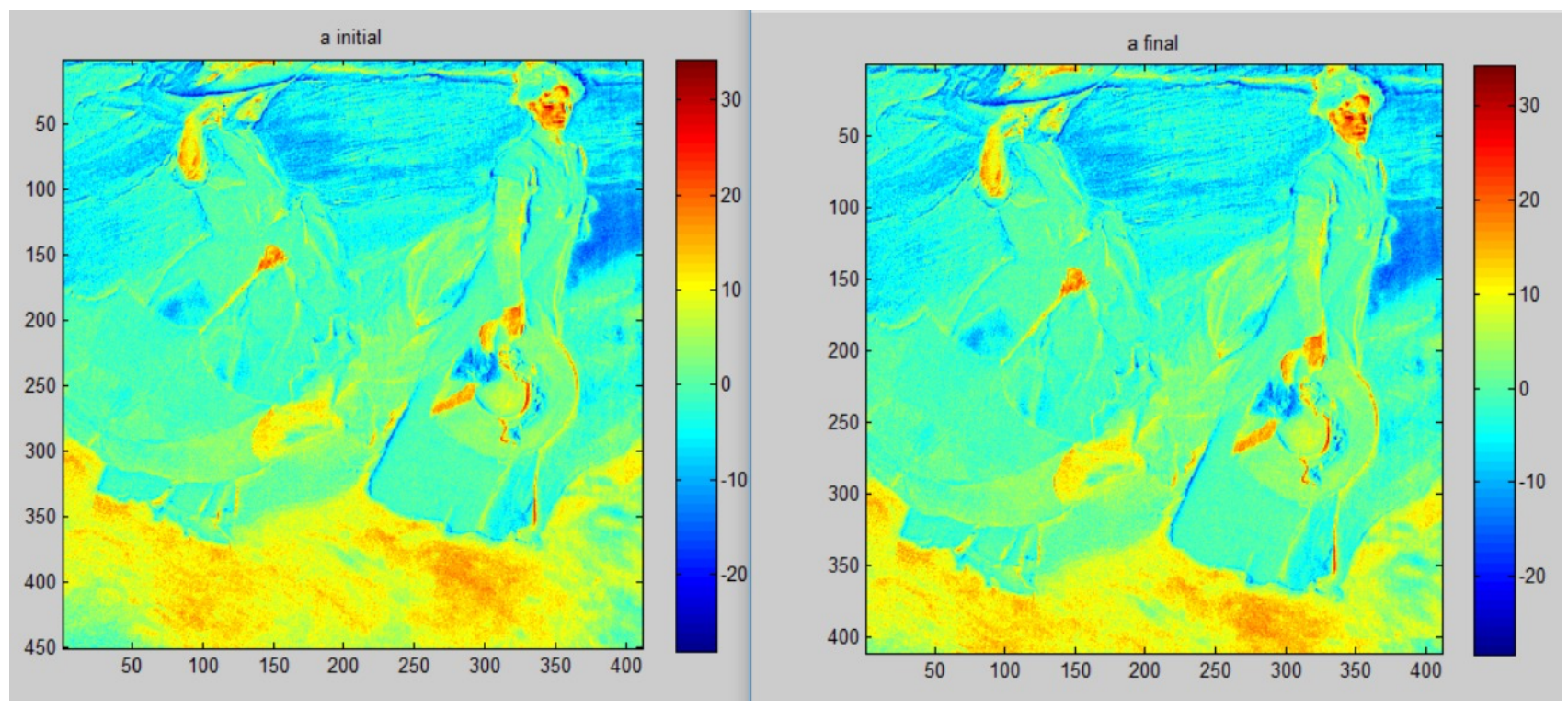

Fig.8.- $a$ coordinates on the paint. Original values (left) and obtained values (right).

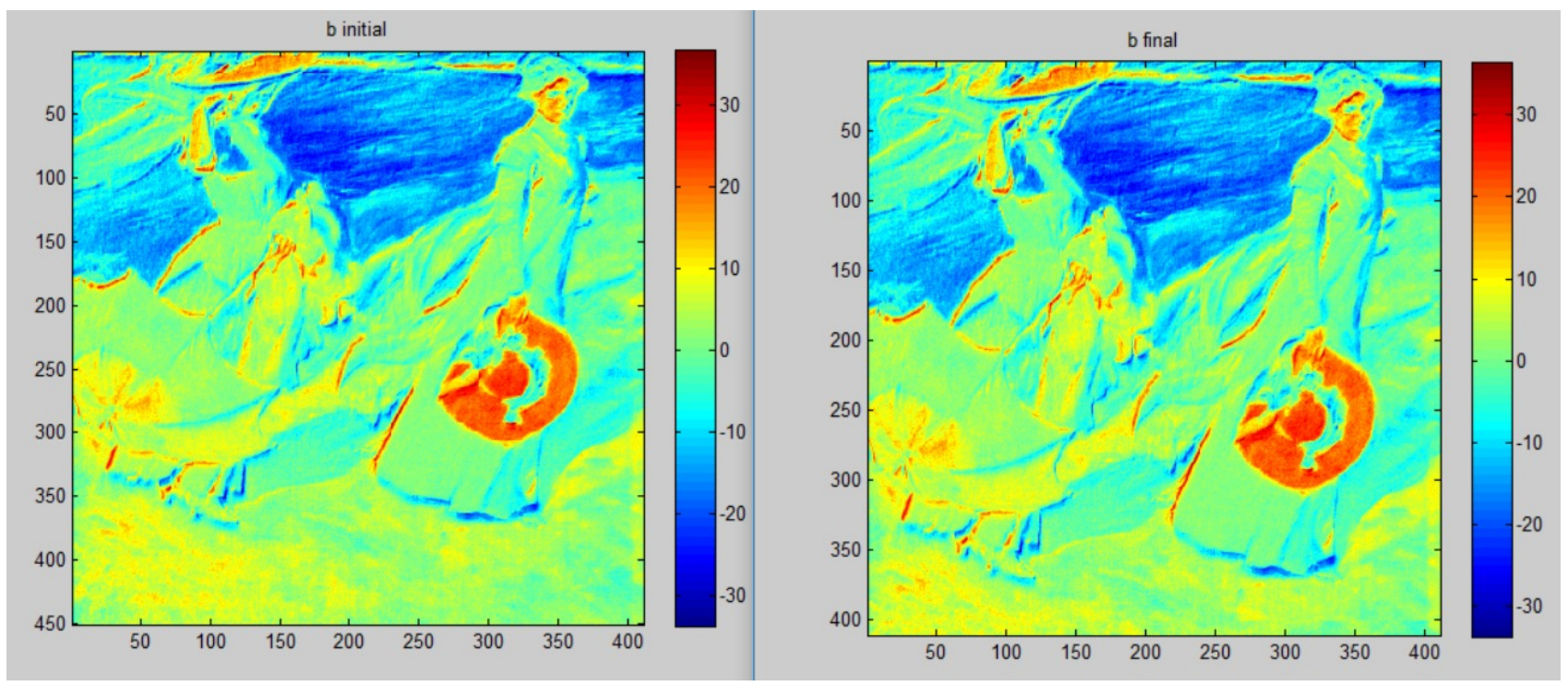

Fig.9.- $b$ coordinates on the paint. Original values (left) and obtained values (right). 


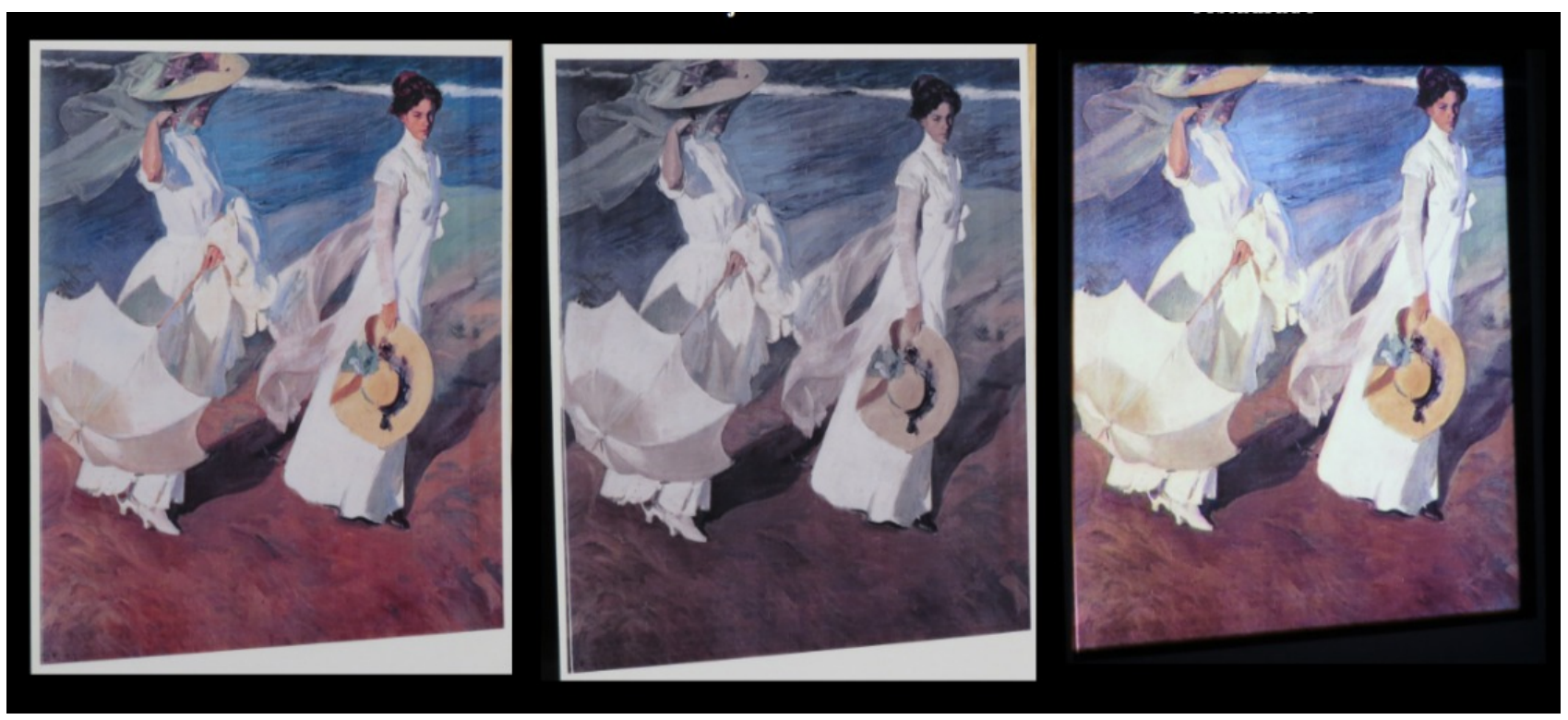

Fig.10.- Image of lighted paints. Original paint (Left). Aged paint with yellow filter (center). Restored paint (left)

\section{CONCLUSIONS}

Cultural heritage have specific requirements for lighting systems. In order to reduce as much as possible the photochemical damage and to reproduce with quality the visual properties of the art goods, mainly the color, it is necessary to develop new devices. Nowadays LED technology make possible to obtain point to point spectral selective lighting systems. Since multispectral image systems make possible to obtain spectral information with high spatial and spectral resolution it is possible to develop systems which light each point of the art good with an optimized spectral distribution. This technology fulfill many different requirements of curator and museum responsible. For example, it would make possible to reduce photochemical damage but it can light art goods as a photonic restoration system which can be used as a help tool for the restores or even as a way to show the good as it was in some historical time.

\section{REFERENCES}

[1] Pavlogeorgatos G. "Preservation of material cultural heritage.Thessaloniki, Greece": Paratiritis Publishing House S.A. ISBN 960-374-253-8 (2003)

[2] Camu3o D, Grieken RV, Busse HJ, Sturaro G, Valentino A, Bernardi A, Blades A, Shooter D, Gyssels K, Deutsch F, Weiser M, Kim O, Ulrych U. "Environmental monitoring in four European museums. Atmospheric Environment";35(1):S127-40. (2001)

[3] Schultz AW, editor. "Caring for family treasures". New York: Harry N. Abrahms Inc.; (2000).

[4] Camu3o D. "Microclimate for cultural heritage". Amsterdam: Elsevier; (1998)

[5] Cuttle, C., "Damage to museum objects due to light exposure", Light. Res. Tech., 28(1), 1 -9 (1996).

[6] Cuttle C., "Lighting works of art for exhibition and conservation", Light.Res.Tech. 20(2), 43-53 (1988).

[7] Hoon, K. and Hong-Bum, K., "New evaluation method for the lightfastness fo colored papers by radiant energy", J. Illum. Eng. Soc., 17-24, winter (2000).

[8] Garcia, I., "La conservación preventiva y la exposición de objetos y obras de arte", KR (1999).

[9] Schaeffer, T., "Effects of Light on materials in collections", Getty conservation Institute, (2001). 
[10] CIE. "Control of damage to museum objects by optical radiation"Q. CIE Publication No 157. Vienna: CIE Central Bureau; (2004).

[11] Brommelle NS. "The Russell and Abney report on the action of light on water colours". Stud Conservation;9:140$151,(1964)$

[12] G Muething, R Waller, F Graham, "Risk assessment of collections in exhibitions at the Canadian museum of nature", JAIC 44, pp 233-243, (2005)

[13] Ballard MW. Conference reports: "the care and preservation of modern materials in costume collections". American Institute for Conservation News;23(3):19.(1998)

[14] Thomson G. "A new look at colour rendering, level of illumination, and protection from ultraviolet radiation in museum lighting". Stud Conservation;6:49-70, (1961)

[15] Snyder J, Montague J. "Caring for your art, a guide for artists, collectors, galleries and art insitutions", New York: Allworth Press; (2001).

[16] Francoise Viénota, Guillaume Corona,b, Bertrand Lavédrinea , "LEDs as a tool to enhance faded colours of museums artefacts", , Journal of Cultural Heritage 12 431-440. (2011)

[17] Monica F. Delgado,1 Carl W. Dirk,1* James Druzik ,'Lighting the World's Treasures: Approaches to Safer Museum Lighting", ,2 Nathan WestFall1,Color Res App, Volume 36, Number 4, 238-254, (2011).

[18] Michael Scuello,1 Israel Abramov,1* James Gordon,2 Steven Weintraub3, Museum Lighting: "Optimizing the Illuminant", Color Res App, Volume 29, Number 2, 121-127, (2004).

[19] P Iacomussi, G Rossi, "Innovative optimized light source for works of arts", Colour and Light in Architecture_First International Conference Proceedings (2010)

[20] J Muñoz, D Vázquez, A Alvarez, Á García, JA Herraez, R Ontañon, “Selective Spectral LED Lighting System Applied in Paleolithic Cave Art", LEUKOS, 00:1-8, (2015).

[21] Raymond H. Lafontaine, "Seeing through a Yellow Varnish: A Compensating Illumination System", Studies in Conservation, Vol. 31, No. 3, pp. 97-102. (Aug., 1986)

[22] Jens Stenger1, Narayan Khandekar2, Annie Wilker2,3, Katya Kallsen4, Daniel P.Kirby2, Katherine Eremin, "The making of Mark Rothko's Harvard Murals", Studies in Conservation VOL. 61 NO. 0, pp 331-347.( 2016)

[23] Fabiola Almarza Lorente-Sorolla," Joaquín Sorolla : técnica artística”, Madrid, Tecnos, (2015)

[24] Santiago Mayorga Pinilla, Daniel Vázquez, Antonio Álvarez, Carmen Muro, Javier Muñoz, "Spectral damage model for lighted museum paintings: Oil, acrylic and gouache”, Journal of Cultural Heritage 22, pp 931-939. (2016)

[25] Jens Stenger, Narayan Khandekar, Ramesh Raskar, et al,and Christina Rosenberger, "Non-invasive colour restoration of Mark Rothko's Harvard murals using light from a digital projector", Proceeding CCIP (2006)

[26] J. A. Quiroga, J. Zoido, J. Alonso, and E. Bemabeu, "Colorimetric matching by minimum-square-error fitting", App. OpticsS, / Vol. 33, No. 26, 1994. 